\title{
Protection of Upper Respiratory Tract, Mouth and Eyes
}

\begin{abstract}
Pathogenic bacteria and viruses may invade via upper and lower respiratory tract and via eye mucosa. When an infected person coughs or sneezes heavily, small, invisible droplets with the infective agent may reach a good distance from the source. By using the right form of protection at the right time, infection and disease are prevented. The present chapter is focused on the protection against airborne infections.
\end{abstract}

\section{Keywords}

Airborne infections $\cdot$ Aerosol $\cdot$ Droplets $\cdot$ Respiratory protection equipment $\cdot$ N95 respirators $\cdot$ P3 masks $\cdot$ Surgical masks $\cdot$ Face mask $\cdot$ Goggles $\cdot$ Cap

\subsection{Purpose}

- To protect patients, staff, visitors and the environment against contaminated air and droplets, according to the occupational health and safety legislation [1-5].

- To prevent direct transmission from contaminated hands to nose, mouth and eyes, and use of the uniform as a handkerchief when coughing and sneezing [6, 7].

\subsection{Comprise}

- Contact with infectious patients, according to the isolation procedures.

- When performing sterile procedures.

- When in close contact with patients who are in an infection-prone situation, for example, during operations and patients with compromised immune system. 
- Contact with wounds and tissues and/or in direct contact with sterile equipment used invasively or when present during ongoing invasive procedures.

- Self-protection against splashes/aerosol of biological material (trachea suction, vomiting, cough, diarrhoea, secretions, diathermy, etc.).

- Patient with suspected contagious respiratory infection-during transport, examination, treatment, etc.; use a face mask-also on the patient—-to protect others and the environment from contamination.

- When cleaning and disinfecting contaminated rooms like isolates and when handling used patient equipment/machinery with organic material (ventilator, CPAP, etc.) and used patient textiles, infectious waste and bio-organic waste.

- During work with plumbing and construction with increased risk of soil, splatter, aerosols or dust particle clouds, such as working with instrument channels in the patient rooms and surgical departments, ventilation systems, sinks, sewer, water leakages with fungal growth, etc.

- Caps should always be used when putting on masks to protect hair.

\subsection{Responsibility}

Hospital management should ensure an infection control programme that informs all employees about the standards of hygiene and infection control at the hospital. Furthermore, to provide resources to the acquisition, stock reserves and logistics of adequate personal protective equipment (PPE), also for emergency situations [5, 8].

Department management is responsible for training, use and control of face masks, respirators and eye protection and that the equipment and written guidelines are available [5].

Each user is responsible for the proper use of PPE at the right time and in accordance with current guidelines.

\subsection{Practical Measures}

The following are available in all relevant departments/posts:

- Guidelines-written — for the use of a face mask/respirator/eye protection.

- Surgical masks: put a date on the box when it opens. Only surgical masks of good quality are used. Other face masks - thin and of poor quality-fastened behind ears should never be used in the healthcare system because of no protective effect.

- Respiratory protection-P3 mask — with and without valve, separately packed. Put the date on the box.

- Surgical face masks with visor.

- Face shield. 
- Goggles. Single-use or multi-use goggles that can be disinfected and autoclaved between uses.

- Cap/hood/head or neck protection (phantom hood, operation caps)—always when using masks.

- Access to good hand hygiene — hand disinfectant — at the place where the PPE is used.

\subsubsection{Protect Head, Hair and Neck}

When airways, mouth and eyes are protected, the hair and head should also be covered simultaneously. Many people have long hair that can come in contact with the patient, bedding or equipment which can lead to transmission of infection to other patients, in addition to themselves becoming a carrier.

NB! Always use cap/hood/head protection when using surgical mask or other PPE.

\subsubsection{Face Shield and Goggles}

These may be single-use or multi-use. Single-use devices are thrown away immediately after use. Surgical mask with visor may protect against direct spills and splashes. A complete face shield protects against direct splashing.

The multi-use equipment (check with infection control personnel) is soaked in chloramine $5 \% 1 \mathrm{~h}$ (or household chlorine) before laundered in soapy water or washed in the instrument washing machine by more than $85^{\circ} \mathrm{C}$ or autoclaved. It is stated on the package if the goggles may be autoclaved.

\subsubsection{Surgical Mask}

Quality-controlled surgical face mask is disposable and used for:

- Surgery and sterile procedures.

- Protection for infection-susceptible individuals/situations.

- Protection against influenza (seasonal influenza), RSV, parainfluenza virus, Mycoplasma, enterovirus, metapneumovirus, adenovirus, coronavirus, human bocavirus and other acute respiratory infections transmitted through respiratory tract [1].

- Patient with respiratory infection_coughing, sneezing — put a surgical mask on the patient during transportation, examination, etc.

- Patient with uncontrolled wound secretion-wound infection.

- MRSA and VRE, including suspected carrier state [1]. 
- Multiresistant gram-negative bacteria-including suspected cases [1].

- Norovirus—vomiting and diarrhoea—or suspected norovirus or the like [1].

- Clostridium difficile - especially when much diarrhoea [1].

- EHEC-entero-haemorrhagic E. coli-and occasionally with other enteropathogenic bacteria (Salmonella, Shigella, Campylobacter, Yersinia, etc.) when uncontrolled diarrhoea and vomiting, especially in children [1].

\subsubsection{Putting On and Taking Off Putting On}

- Disinfect your hands.

- Put on the cap — thin operating hood—-that collects all hair. Pull it over your ears.

- Disinfect your hands.

- Take the mask from the surgical mask box, and take only one mask. The box must have the date of opening. All boxes that have been exposed to infection should be discarded afterwards.

- Put the face mask over your mouth and nose with a drawstring at the back of the head/top and the other on the neck.

- Adapt the face mask that has metal string over the nose-so that it fits tightly and comfortably around the mouth and nose.

- Replace the face mask between each patient/situation/procedure or after 2-6 h if you are with the same patient or when it is wet on the inside. Avoid changing the mask if this can cause more contamination and risk, for instance, during surgery. Surgical masks are usually not changed during surgery.

- Never go with a face mask under the chin or around your neck! It is usually heavily contaminated by mouth and nose secretion after use and by splatter from the patient.

\section{Taking Off}

- Perform hand hygiene.

- First take hold of the string in the neck and loose this while you bend forward. The lower part of the mask then falls away from the face. Then gently loosen the string on the head, and gently put the mask into the waste container.

- Face masks should not come in contact with hair or clothes.

- Dispose in regular waste during normal use or infectious waste if infection.

- Perform hand hygiene afterwards.

- Grip the cap back and carefully pull it off while bending forward, and put it into the waste container.

- Perform hand hygiene afterwards.

\subsubsection{Respiratory Protection (P3 Mask, N95 Mask)}

Filtering half masks and guidelines for use of respiratory protection should be available at relevant clinical departments. 


\subsubsection{Single-use device!}

\section{P3 mask (some with exhalation valve) is used as protection for}

- Suspected tuberculosis and always during operations/intervention on suspected tuberculous tissue.

- Induced sputum if suspected having pulmonary tuberculosis.

- Penicillin-resistant Pneumococci-symptoms from the respiratory tract.

- Varicella zoster (chickenpox) and morbilli (measles) if not immuned. Pandemic influenza, avian influenza, SARS, MERS-CoV (Middle East respiratory syndrome coronavirus), polio and certain other enteroviruses associated with paralysis, etc.

- Ornithosis ("psittacosis")

- Haemorrhagic fever or such suspected disease (Ebola, Lassa, Crimean-Congo haemorrhagic fever, etc.)

- Other high-risk diseases: suspected brucellosis, anthrax, tularemia, diphtheria, melioidosis, plague, $\mathrm{Q}$ fever and rickettsioses.

- Laser treatment for suspected human papillomavirus and cancer treatment.

- Surgical procedures in patients with severe infectious diseases where there is risk of aerosol formation or release of tissue particles to the air (prion diseases, bloodborne infectious virus, tuberculosis, etc.) [1].

P3 mask is used by the surgical team and during all sterile procedures: in the case of operative treatment of patients with special types of airborne infection such as tuberculosis, etc., see above. If there is an open breathing valve on the $\mathrm{P} 3$ mask, surgical mask must be used outside the P3 mask. P3 mask with covered breathing valve can be used instead.

$P 2$ mask or surgical mask is put on the patient with defined or suspected airborne infection (e.g. tuberculosis, varicella, etc.) during transport, and stay outside isolation units.

\subsubsection{Putting On and Taking Off Putting On}

- Disinfect your hands.

- Put on the cap — thin operating hood—that collects all hair. Pull it over your ears.

- Disinfect your hands.

- Take the P3 mask from the surgical mask box, and take only one mask. Each mask is usually separately wrapped. The box must have the date of opening. All boxes that have been exposed for infection should be discarded afterwards.

- Put the respirator over your mouth and nose with a drawstring at the back of the head/top and the other on the neck. The cap hood underneath makes it easier to put the mask on-it does not slip.

- Adapt the face mask that has metal string over the nose—so that it fits tightly and comfortably around the mouth and nose.

- Test tightness by blowing vigorously or breathing in; leaks are then sensed on the sides of the mask.

- Change the P3 mask after 3-6 h or longer or if it is wet on the inside.

- Avoid change if this may lead to risk of infection. 


\section{Taking off}

Take it off very carefully, as the P3 mask may be used in a serious contagious situation and may be contaminated on the outside.

- Disinfect your hands.

- Grasp the band/string posteriorly, bend forwards and remove the mask gently without coming into contact with the clothing, skin or hair. Do not touch the mask directly.

- Loosen the band in the neck first so that the mask falls forwardly away from the face. Then carefully loosen the band on the head.

- Put the mask gently into infectious waste bin.

- Perform hand hygiene.

- Grip the cap back, bend forwards and carefully pull it off without coming into contact with the skin or clothes and place the mask in infectious waste bin.

- Perform hand hygiene afterwards.

\subsubsection{Goggles/Visor}

Eye protection is always used when there is a risk of splashing of human biological material to the eyes and for protection against highly infectious diseases. In the event of a risk of severe airborne disease, wear tight protective goggles where you can use regular glasses on the inside. Multi-use goggles may be reused after $1 \mathrm{~h}$ of treatment in 5\% chloramine bath (or household chlorine 10,000 ppm) with subsequent soapy water and rinsing.

\subsubsection{Wearing and Removing Goggles Putting On}

- Perform hand hygiene.

- Put on the cap — thin operating hood - that collects all hair. Pull it over your ears.

- In case of severe, dangerous infection, put goggles on outside of a phantom cap that is sitting outside a surgery cap and a P3 mask; see strict isolation.

- Disinfect your hands.

- Goggles are retrieved from the box, usually separately wrapped. The box must have the date of opening. All boxes that have been exposed for infection should be discarded afterwards.

- Put the glasses or shield over the eyes with a rubber band on the occiput. The operation hood under prevents it from slipping.

- Adapt the goggles—so that it fits tightly and comfortably all around the eyes.

- They can be used as long as they are needed.

\section{Taking Off}

Take it off very carefully, as the goggles/face shields may be contaminated on the outside. 
- Disinfect your hands.

- Grasp the band/string posteriorly, bend forwards and remove the goggles/face shield gently without coming into contact with the clothing, skin or hair. Do not touch the devices directly.

- If multi-use: put it carefully into the container with 5\% chloramine. If single-use: put it into the infectious waste bin.

- Perform hand hygiene.

- Grip the cap back, bend forwards and carefully pull it off without coming into contact with the skin or clothes, and place it in infectious waste bin.

- Perform hand hygiene afterwards.

\section{Purchase, Provide and Stock}

"The employer must ensure that protective equipment made available to the worker, meets requirements of regulations on construction, design and manufacture of personal protective equipment" [5]. This should be in accordance with official regulations for the use of personal protective equipment [5, 9].

\subsection{Background Information}

Already in Roman times, it was pointed out by doctor Galen that "when many get sick and die at once, we must look for a common cause, the air we breathe". During the past 10-15 years, emerging and re-emerging microbes and serious global outbreaks have been major challenges to infection control work and to the use of personal protective equipment (PPE). Multidrug-resistant tuberculosis and other multidrug-resistant bacterial organisms-MDROs-are increasing worldwide. Very serious virus epidemics are emerging, such as SARS in 2003, avian flu in 2005, the pandemic influenza in 2009, MERS-CoV outbreak from 2010 and the Ebola outbreak in West Africa in 2014, re-emerging in 2017 $[1,10-22]$. Most cases of these serious, life-threatening diseases may be transmitted via air, droplets and re-aerosols, from patients, carriers and the environment.

An adult breathes in at rest 5-8 litres of air per minute, at medium heavy work 30-40 L and at great exertion 70-100 litres of air per minute. In small rooms and with a high air contamination of infectious agents, some contaminants will be drawn into the respiratory tract. It has been demonstrated that when a person coughs or sneezes, drops, droplets and droplet nuclei from the mouth and nose may reach up to $9 \mathrm{~m}$ from the source [2].

Surgical masks and respiratory protection (filter masks) are defined as "equipment that can help prevent the spread of microbes from one person to another" [2, 3]. The difference between surgical mask and respiratory protection is that surgical masks primarily protect the patient and sterile area/equipment against mouth and nose secretion from healthcare professionals, while respiratory protection protects healthcare workers and others from airborne infections from nearby sources of infection $[3-5,14,23]$. 
Fig. 13.1 Spread of large and small drops when sneezing: "Norway has got a new epidemic with elbow-coughing and -sneezing people. This is a bad hygienic behaviour under normal conditions and a society- critical handling during epidemics" (Source: Illustration photo Gorm Kallestad/Scanpix, Andersen BM. Dagbladet 12.11.2009. Article)

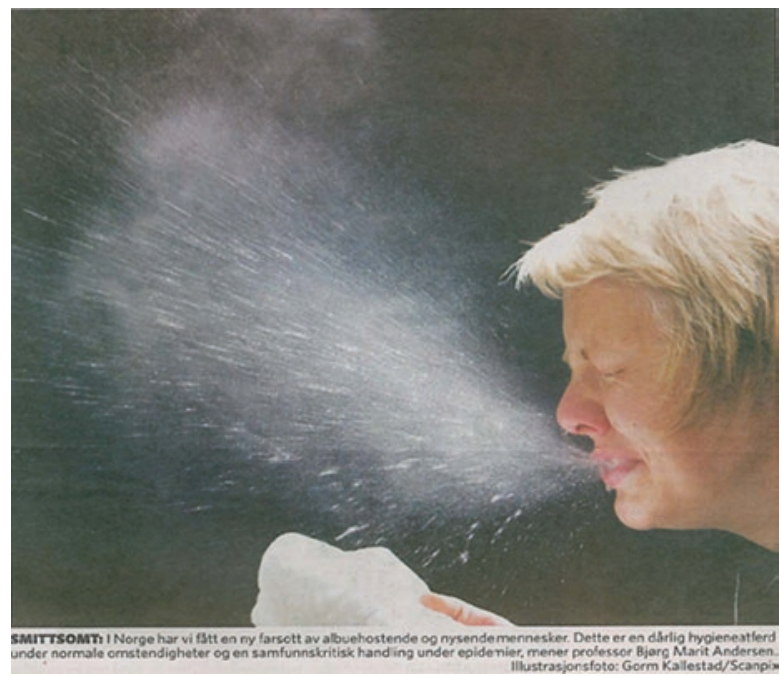

However, surgical masks are not approved as protection against airborne infections: [5, 14, 24, 25] "Harmful microorganisms (bacteria, viruses, fungi) or components of microorganisms (e.g. endotoxins) may occur in air, either in dust, smoke or aerosols, or even finer distributed as droplet nuclei where all liquid has dried in. Surgical masks only protects against splash and drop, not against airborne infection. Therefore, to protect against airborne infection, wear respiratory protection. In most situations, a filtering half mask will provide a good protection. Particle filter class P2 protects against most spores of fungi. At risk of exposure to airborne viruses and bacteria, especially tuberculosis, particle filter P3 must be used. In particularly dangerous situations, during prolonged work or if carrying a beard, should special breathing systems be used" [5] (Fig. 13.1).

\subsubsection{Protection Against Airborne Infection}

Many human pathogenic bacteria and viruses invade via upper and lower respiratory tract [1]. Some viruses may also invade via eye mucosa, such as influenza, hepatitis $\mathrm{B}$ and $\mathrm{C}$ and HIV.

Carl Schiøtz, a Norwegian professor in hygiene and infection control, wrote in the textbook of hygiene in 1937 (80 years ago) that the most important measures against communicable diseases are the following: (1) isolation of the sources of infection (home or hospital), (2) disinfection of the exposed rooms and equipment, (3) vaccination if vaccine-preventable disease, (4) quarantine, (5) food hygiene and (6) insect eradication [26]. He noticed that airborne infection was considered to be "the most important form of transmission of infections at our latitude" [26].

Schiøtz meant that drops from the respiratory tracts were large and heavy and went 1.5-2 m away, while saliva droplets went in "up to $20 \mathrm{~m}$ distance from 
high-speaking people and they could stay floating in the air for several hours" [26]. This was important for the spread of "flu, colds, pneumonia, pest-pneumonia, tuberculosis, pertussis, measles, small-pox, chickenpox, scarlet fever, rubella, diphtheria, poliomyelitis, epidemic cerebrospinal meningitis and several other diseases" [26]. He also focused on inhalation of dust containing microbes [26].

The introduction of antibiotics in post-war times and the sharp reduction of lung tuberculosis caused many to forget that it was something that was infected via air. Tuberculosis has been "recognized" as an airborne infection at least in 100 years, although some still believe that short-term exposure to the patient does not lead to infection. This perception has led to multiple outbreaks of multiresistant tuberculosis, including in the United States [27].

\subsubsection{The Definition of Airborne Infection Is Still Controversial}

Airborne transmission is most often downgraded by the health authorities to contact and droplet transmission - traditionally within $1 \mathrm{~m}$ from the patient. This applies to healthcare professionals who are going to treat patients with severe, deadly infections where surgical masks are estimated "good enough" [10-16, 23-25, 28-31].

Droplet transmission is a definition that may put healthcare personnel at risk during dangerous situations since it is still a "form of contact transmission" [17]. The CDC definition from 2007 is upgraded since 2004 but is still very vague and controversial; see the following quotations [17]:

Droplet transmission is generated when "an infected person coughs, sneezes, or talks - or during procedures such as suctioning, endotracheal intubation, cough induction by chest physiotherapy and cardiopulmonary resuscitation. ---The maximum distance for droplet transmission is currently unresolved,---Historically, the area of defined risk has been a distance of $\leq 3$ feet around the patient----investigations during the global SARS outbreaks of 2003 suggest that droplets -- could reach persons located 6 feet or more from their source. ---- Thus, a distance of $\leq 3$ feet around the patient is best viewed as an example of what is meant by 'a short distance from a patient' ---- it may be prudent to don a mask when within 6 to 10 feet of the patient or upon entry into the patient's room, especially when exposure to emerging or highly virulent pathogens is likely--" [17].

"Droplet size is another variable under discussion --- defined as being $>5 \mu \mathrm{m}$ in size. Droplet nuclei, particles arising from desiccation of suspended droplets, have been associated with airborne transmission and defined as $\leq 5 \mu \mathrm{m}$ in size-----particle dynamics have demonstrated that a range of droplet sizes, including those with diameters of $30 \mu m$ or greater, can remain suspended in the air" [17].

The worst example until now is the recommendation of "contact and droplet transmission within $1 \mathrm{~m}$ " with the use of surgical masks (within $1 \mathrm{~m}$ from the patient), by WHO, the first phase (3 months) of the SARS epidemic in 2003, where $90 \%$ of those who became ill during this first phase were health professionals [28]. The same was done during the avian influenza epidemic in 2005 and mostly throughout the influenza pandemic in 2009 [29]. WHO and CDC recommended both 
"contact and droplet transmission" measures during the first 6 months of the Ebola epidemic in 2014 [1, 30]. During some of the most serious global epidemics that have happened in the last 80 years, healthcare personnel were exposed to infection without proper protective equipment and had the highest death rate associated with work-related infection [10-17, 30, 31].

During the SARS outbreak in Toronto, Canada, 169 health personnel were infected with nosocomial SARS, and 3 of these died [14, 31]. Infection control personnel in Toronto insisted that SARS was primarily transmitted through large droplets-within $1 \mathrm{~m}$-and that there was lack of evidence-based documentation for airborne infection! [31] Despite the fact that health professionals requested it, the respiratory protection (N95) was not handed over to the staff, and the outbreak continued for a long time [31]. A State Investigation Commission came to the following bottom line conclusion: Safety comes first and reasonable measures to reduce the risk of healthcare professionals do not have to wait for scientific evidence [31].

In the event of outbreaks of less severe airborne infections such as common flu, RSV, Mycoplasma, adenovirus, metapneumovirus, etc., it is important to protect healthcare professionals from infection. The purpose is that infected personnel should not be "vectors" of infections in the hospital. In addition, a large outbreak among the staff may cause that patients with life-threatening diseases like heart attack, trauma, etc. do not get the necessary treatment.

Despite all the controversies surrounding airborne transmission, a number of international guidelines for the use of respiratory and face protection equipment have been developed under varying epidemiological conditions and experiences over the past 100 years. Recent surveys and experiences show that Schiøtz and other researchers had correct facts and guidelines according to airborne infections. Secrets from the respiratory tract can go far off $9 \mathrm{~m}$ or more, for example, when coughing and sneezing, and pathogenic viruses and bacteria are detected in the air in rooms with infected patients [2, 14, 17, 18, 20, 21, 26, 32-43]. Airborne MRSA and other multiresistant bacteria may be a greater problem than previously thought $[17,18$, 20, 42]. Even Clostridium difficile spores may become airborne under certain conditions [43]. Today, it is also known that most microbes are strong, surviving organisms outside the body $[1,44]$. They can also survive on the outside of the protective equipment and even re-aerosol from these and even penetrate a wet mask [1, 4, 44-48]. Respirators (half masks) are more expensive (about 4 USD) than surgical mask $(<0.1$ USD). Because of a shortage during large outbreaks, it has been attempted to decontaminate respirators for reuse. However, this is not effective, is not recommended and cannot be done with disposable equipment [49].

\subsubsection{Disease Spread To and Through Air}

Most infectious agents are spread through contact, blood, drops, droplets, drop nuclei (aerosol), airborne on dust particles and often in several ways simultaneously $[12,13,17,23,33-43,50-52]$. 
Transmission of microbes from the respiratory tract to the air occurs by breathing, speech, cough, sneezing, laughing, singing or other aerosol-generating procedures. Sneezing usually leads to greater amount of microbes transferred to air than coughing [51]. How long the contaminant stays alive in the air depends on the agent, temperature, humidity, virus dose response, particle size and presence of other material [50-56]. Some larger drops are deposited close to the patient, and smaller dropsdroplet nuclei-pass into a floating phase in the air and are falling slowly over time, such as influenza A virus [2, 50-56]. Transmission of microbes via small particles and droplet nuclei from influenza patients is not adequately controlled by the use of surgical mask [50-52]. Airborne transmission always includes contact transmission and often re-aerosols from the environment [18-21, 39, 42-44, 55-61].

Transmission to the air from the skin occurs via the release of millions of skin particles where approximately $10 \%$ carry bacteria or virus from the skin or wound.

Re-aerosols from infectious particles whirled up in the air, for instance, during bed-making, dry mopping of contaminated floor surfaces, from contaminated areas in the room during air currents or when the door is opened or closed quickly [62]. Re-aerosols of pathogenic microbes may be important because of a long survival in the environment, for days, months and years [1,44]. Influenza A virus survives on paper, textiles and equipment for more than 3 weeks and can become airborne [5561]. Influenza A virus is very contagious via aerosols and small airborne droplets [56].

\subsubsection{Reduction of Airborne Transmission}

Microbial load in the air depends on cleaning and air exchange [5, 10-14, 63]. Proper cleaning and ventilation with a positive pressure of filtered air reduce the load in the operating units or during protective isolation. Decontamination and cleaning of rooms, textiles and surfaces and a good air exchange with a negative air pressure are important during isolation of patients with infections.

Air exchange It has been demonstrated that after aerosol-generating procedures such as bronchoscopy, airway suction and intubation, five fresh air changes in the room can greatly reduce air contamination, provided that the source of infection is gone [13].

Respiratory protection prevents people from touching their nose or mouth in an infectious situation and coughing on their own uniforms and thereby exposing themselves to others and to infection $[6,7]$.

Correct use of respiratory protection Most microbes survive for hours to days on the outside of a respiratory protection as shown for bacteriophage, influenza virus and coronavirus [45-47]. This is the reason why respiratory protection should not be reused and why it is not advisable to touch the outside of the mask. During the SARS outbreak in Canada in 2003, the staff reinfected themselves by handling the mask incorrectly and reusing equipment without decontamination [28]. Among 1441 hospital personnel in China, there was a significantly lower incidence of respiratory tract pathogenic microbes among personnel who used respiratory protection with filter N95 $(p=0.02)$ than among personnel using face mask $(p<0.01)$ compared to controls [64]. 


\subsubsection{Surgical Face Mask}

Face mask, covering the nose and mouth, has been used since the Spanish flu in 1919. It was actually developed to protect patients from postoperative infections from the airway flora of the operating team and protect the team against blood and tissue splash from the patient. There is no standard definition of surgical masks, adaptation, leak test or quality of filter [5, 13, 14]. Surgical mask is not approved by the occupational health authorities [3-5, 24, 25]. Nevertheless, there are extensive use and purchase of face masks, especially in the national emergency preparedness plans.

The combination of good hand hygiene and the use of surgical mask within $36 \mathrm{~h}$ after the onset of influenza in an index case may however reduce spread of the flu in the household [65-67]. Volunteer subjects infected with seasonal flu breathed out nearly nine times more virus in small particles, $<5 \mu \mathrm{m}$, than in larger one, $>5 \mu \mathrm{m}$, after the onset of the flu [50]. The use of surgical masks reduced particularly the larger particles and showed a 3.4-fold reduction of virus released to the air [50]. Using surgical face masks can reduce infection and also had some suppressing effect on the spread of infection by SARS [10].

Surgical face mask protects the nose and mouth from splashing and saliva particles but does not protect effectively against bacteria and viruses that are, respectively, from 0.2 to $8 \mu \mathrm{m}(0.0002-0.008 \mathrm{~mm})$ and from 20 to $300 \mathrm{~nm}(0.02-0.3 \mu \mathrm{m})$ in diameter. There is no safe protection against aerosol or droplet nuclei, either through the mask or from the sides of the mask [5, 13, 24, 25, 68]. It is not certain that a mask may stop microparticles of the blood that can be formed by certain procedures, like centrifugation accidents, spray from dental treatment or surgery, etc. $[36,68]$. In such cases, also eye protection should be used.

Persons close to sterile areas can contaminate the area by direct drops of saliva and aerosols that are spilled by speech, coughing and sneezing [2, 13]. A good face mask captures these droplets from the respiratory tract and prevents deposition thereof. It catches drops both ways to some extent, but when the surgical mask is wet, it can become less effective, with some growth of bacteria. It is usually effective for at least $2-3 \mathrm{~h}$.

Face masks with visors protect to some extent both nasal/oral and eye mucosa against infected blood and tissue particles/droplets.

\subsubsection{Respiratory Protection: N95, P3 mask and "dust filters"}

Airborne microparticles of aerosol, drop nuclei and blood drop-bearing bacteria and viruses can be formed during activities of or around the patient (coughing, sneezing, speech, excessive bodily activity, bed-making, dust cleaning etc.).

Respiratory protection such as P3 mask or N95 has shown protective effect in highly severe infections such as SARS, tuberculosis and pandemic influenza [5, 916, 20-23, 56, 64]. Respirators are not designed for children or people with beards, and therefore does not provide full protection for these [5, 23]. 
Respiratory protection is filtering half mask, looks almost like surgical mask and is often called filtering face piece (FFP) respirators or dust filter [5]. They are of different quality (FFP1-FFP3) and capture microbes in both ways. The filter is hepafilter/polypropylene filter with static charge to increase the filter power. FFP2 is equivalent to the US N95 masks that are widely used around the world. The European standard is EN149: 2001 which is equivalent to FFP3 and has a somewhat higher level of protection [13].

Procedures involving large load on the environment around a patient with airborne infection are, for example, bronchoscopy, trachea suction, diathermy aerosol, suction and drilling (orthopaedics, dental treatment, etc.). In such cases, both respirators and eye protection should be used.

\begin{tabular}{|c|c|c|c|}
\hline $\begin{array}{l}\text { Filter } \\
\text { class }\end{array}$ & $\begin{array}{l}\text { Filtration } \\
\text { efficiency }\end{array}$ & Protects against & Comments, some examples \\
\hline $\mathrm{P} 1$ & Low & Solid particles & Use only if the dust is harmless \\
\hline $\mathrm{P} 2$ & Medium & $\begin{array}{l}\text { Solid particles } \\
\text { and liquid } \\
\text { particles }\end{array}$ & $\begin{array}{l}\text { Protects against most types of dust from low } \\
\text { toxicity substances, for example, drilling in } \\
\text { mountains or mines, sweeping pipes, } \\
\text { grinding work, isolation work }\end{array}$ \\
\hline P3 & High & & $\begin{array}{l}\text { Used when the dust contains or may contain } \\
\text { poisonous } \\
\text { or highly toxic particles, carcinogens, radioactive } \\
\text { particles, bacteria, viruses }\end{array}$ \\
\hline
\end{tabular}

Source: Respiratory protection. Directorate of Labour Inspection, 2007 [5]

The P3 mask protects the user and can also be used on patients with specific respiratory infection and then without exhalation valve.

Protection factor is calculated by reducing the degree of pollution in the air. If there is a pollution of $1000 \mathrm{mg} / \mathrm{m}^{3}$ air, a respirator with a protection factor of 500 may reduce the pollution to a residue of $2 \mathrm{mg} / \mathrm{m}^{3}$. That includes inhalation of air through or on the sides of the respiratory protection, which will almost always happen [69-72]. "Protection factors for filtering half masks FFP1, FFP2 and FFP3 matches the protection factors for half mask with respectively filter classes P1, P2 and P3. Motor-assisted filtering air purifying respirators (equipment with a turbo unit) have varying protection factor depending on the equipment design" [5]. A wet filtering mask may be permeable for viruses and bacteria.

The Norwegian Directorate of Labour Inspection indicates protection factors for filtering respirators as follows [5]:

\begin{tabular}{l|l|l|l|l}
\hline Filter & P1 & P2 & P3 & Gas \\
\hline Half mask & 4 & 12.5 & 50 & 50 \\
\hline Full mask & - & 16 & 1000 & 2000 \\
\hline
\end{tabular}

Lower protection is expected, because it is often leaked due to poor adaptation; factor 10 is for filtering half mask classes 2 and 3, and factor 100 is for full face masks. "Protection factor for both supplied air and air purifying respirators with 
half and full face masks also require a good fit, and this cannot be expected if beard, glasses or the like, in squeeze along the edge of the mask" [5].

Requirements for filtering half masks [5, 12, 13, 69-72].

\begin{tabular}{l|l|l|l}
\hline Mask class & Total efficiency & Total leakage & Protection factor \\
\hline P1 & $78 \%$ & $22 \%$ & 4.5 \\
\hline P2 & $92 \%$ & $8 \%$ & 12.5 \\
\hline P3 & $98 \%$ & $2 \%$ & 50 \\
\hline
\end{tabular}

P3 has the highest protection factor with 50 times cleaner air inside the mask than outside. The mask's overall efficiency depends on the filter quality of the mask, fitting the face shape (leakage) and leakage through any exhalation [5, 12, 13, 69-72].

Fit test is the control and training using special odour tests that the person perceives within the mask if it is not tight enough $[5,12,13]$.

\subsubsection{Many Different Models}

In a study of five models of the N95 mask (3M 1860S cup, 3M 1870 flat fold, Kimberly-Clark PFR95 duckbill, SafeLife T5000 cup added with iodine and GlaxoSmithKline Actiprotect cup, added with lemon acid), all five types had more than $95 \%$ efficiency: $-0.8 \mu \mathrm{m}$ particles of H1N1 influenza virus and corresponding inert particle sizes [69]. Filtration efficiency was largely based on particle size [69]. So-called elastomeric masks appear to be more effective than regular filter masks [70]. Studies show considerable variation with regard to protection, and for some dangerous, microbial agents, $95 \%$ protection may be too low [71, 72].

\subsubsection{Other Types of Respiratory Protection}

- Turbo Equipment (PAPR = -Powered air-purifying respirators) with P3 filter (protection factor 500-2000) - may have problems concerning the disinfection of battery-operated, recycling systems, and is dependent on a good training $[5,12,13]$.

- Fresh air/pneumatic equipment (protection factor, 100-100 000) is used for particularly risky situations of special personnel in laboratories and when working in areas with severe epidemics. However, there may be serious infection problems regarding disinfection of reuse systems (filters, mechanical/electrical appliances).

\subsubsection{Strategic Stockpile}

During non-epidemic times and with low-virulent microbes, respiratory protection (N95 or P3 masks) are not used for other than special types of respiratory infections and pulmonary tuberculosis. This may influence on the state of readiness for major outbreaks such as pandemic influenza. Consumption of masks can be very large as during the SARS outbreak in 2003, where a Canada-based hospital with SARS outbreak used up to 18,000 N95 masks each day [13].

The durability of respiratory protection equipment is good-up to 10 years or more in storage. Items made with rubber or rubber parts should be checked, and 
there should be some systemic rotation in the warehouse [49]. At OUH, Ullevål, there has been a strategic stockpile system of such equipment with replacement as required [8]. The experience from Norway is that the national health authorities have been unprepared for stockpiling of emergency response requirements for PPE, also during the influenza pandemic of 2009 [29]. The market may soon be empty for respiratory protection masks during serious outbreaks such as SARS and Ebola virus. Using several surgical face masks superposed did not have enough protective effect [73]. During the SARS epidemic, the Chinese healthcare personnel made their own masks of 12 layers of gauze that supposedly would work well.

\subsubsection{Goggles/Visor}

This is used when there is risk in soil and splatter of biological materials and to protect against highly dangerous infection. If there is a risk of transmission of severe respiratory infection, tight-fitting goggles are used. The goggles can be reused after $1 \mathrm{~h}$ of treatment in $5 \%$ chloramine, followed by washing with soap and water, and they may also be reprocessed and decontaminated in a washing machine at $>85^{\circ} \mathrm{C}$.

\subsection{Conclusion}

Controversial issues concerning airborne infection and protection against "droplet transmission" should be further studied. Particle studies; ventilation variations; kinetics; the effect of humidity, temperature and filter types; re-aerosols from dust; environment and PPE equipment; and the survival of microbes in the environment should be better studied. This is the case for most important microbial agents: bacteria, viruses and fungi. Respirators should be preferred over surgical masks when there is suspected droplet or airborne transmission. This choice is essentially a misunderstood price and attitude problem.

\section{References}

1. Andersen BM. Microbiology and infection control. Handbook of hygiene and infection control in hospitals. Part 1. Borgen: Fagbokforlaget; 2014.

2. Bourouiba L, Dahandschoewercker E, Bush JWM. Violent expiratory events: on coughing and sneezing. J Fluid Mech. 2014;745:537-63.

3. Norwegian Directorate of Labour Inspection. Protection of workers from the risks when working with biological factors. Norwegian Law Dept 1. 27/1997.

4. European Parliament and Council Directive 2000/54/EC of 18 September 2000 on the protection of workers from the risks related to exposure to biological agents at work (seventh individual Directive according to Article 16. 1 of Directive 89/391/EEC).

5. Norwegian Directorate of Labour Inspection. Respiratory Protection; November 2007.

6. Macias AE, de la Torre A, Moreno-Espinosa S, Leal PE, Bourlon MT, Ruiz-Palacios GM. Controlling the novel A (H1N1) influenza virus: do not touch your face! J Hosp Infect. 2009;73:280-1. 
7. Andersen BM. European Centre for Disease Prevention and Control - swine flu guidelines: "cough hygienically" into your sleeve? J Hosp Infect. 2010;75:73-4.

8. Andersen BM. Serious, communicable disease - personal protective equipment-PPE. In: Handbook of hygiene and infection control in hospitals. Oslo: Ullevaal University Hospital; 2008. p. 567-8.

9. Norwegian Directorate of Labour Inspection. Norwegian standard. Respiratory protection. Breathing equipment with fresh air hose connected to a full face mask, half mask or mouthpiece means. Requirements, testing, mark. NS- EN 138; 1994.

10. WHO. Non-pharmaceutical interventions for pandemic influenza, national and community measures. Emerg Infect Dis. 2006;12:88-94.

11. CDC. Interim guidance on infection control measures for $2009 \mathrm{H} 1 \mathrm{~N} 1$ influenza in healthcare settings, including protection of healthcare personnel. Atlanta: CDC; 2010.

12. Coia JE, Rithcie L, Adisesh A, et al. Guidance on the use of respiratory and facial protection equipment. J Hosp Infect. 2013;85:170-82.

13. Bunyan D, Richie L, Jenkins D, Coia JE. Respiratory and facial protection: a critical review of recent literature. J Hosp Infect. 2013;85:165-9.

14. Harriman KH, Brosseau LM. Controversy: respiratory protection for healthcare workers. Medscape Infect Dis. 2011; April 28.

15. ECDC Health Information. Personal protective measures for reducing the risk of acquiring or transmitting human influenza; 19 May 2009.

16. Liverman CT, Harris TA, Rogers MEB, Shine KI. Respiratory protection for healthcare workers in the workplace against novel H1N1 influenza A. Washington, DC: Institute of Medicine; 2009.

17. Siegel JD, Rhinehart E, Jackson M, Chiarello L. 2007 guideline for isolation precautions: preventing transmission of infectious agents in healthcare settings. Atlanta: CDC; 2007.

18. Bernard MC, lanotte P, Lawrence C Goudeau A, Bernard L. Air contamination around patients colonized with multi drug-resistant organisms. Infect Control Hosp Epidemiol. 2012;33:949-51.

19. Hamel M, Zoutman D, O'Callaghan C. The exposure to hospital room is fed as a risk factor for healthcare-associated infection. Am J Infect Control. 2010;38:173-81.

20. Gehanno JF, Louvel A, Nouvellon M, Caillard JF, Pestel-Caron M. Aerial dispersal of methicillin-resistant Staphylococcus aureus in hospital rooms by infected or colonised patients. J Hosp Infect. 2009;71:256-62.

21. Shiomori T, Miyamoto H, Makishima F, Yoshida M, Fujiyoshi T, Udaka T, et al. Evaluation of bedmaking-related airborne and surface methicillin-resistant Staphylococcus aureus contamination. J Hosp Infect. 2002;50:30-5.

22. Guidelines for preventing the transmission of Mycobacterium tuberculosis in health-care facilities, 1994; Notice. Fedreal register 1994; 59.

23. U.S. Food and Drug Administration. Masks and N95 respirators. Personal protective equipment.

24. OSHA. Respiratory protection standard; 2011.

25. NIOSH. Work place safety and health topics: respirator; 2011.

26. Schiødz C. The infectious diseases. Textbook in hygiene. Oslo: Fabritius \& Sønners Forlag; 1937. p. 232-51.

27. Andersen BM. Mycobacterium tuberculosis. In: Bacteria and disease. Epidemiology, infection and immunity. Oslo: Gyldendal Academic; 2005. p. 409-27.

28. Andersen BM. SARS. In: Microbiology and infection control. Handbook of hygiene and infection control in hospitals. Part 1. Bergen: Fagbokforlaget; 2014. p. 319-43.

29. Andersen BM. Pandemic influenza. In: Microbiology and infection control. Handbook of hygiene and infection control in hospitals. Part 1. Bergen: Fagbokforlaget; 2014. p. 216-32.

30. Andersen BM. International infection control guidelines may not protect against Ebola. Hospital Healthcare; 2015. p. 1. 
31. Ontario Ministery of Health and Long-term Care. SARS Commission- Spring of fear: Final report. Health Gov.; March 24, 2011.

32. Li Y, Leung GM, Tang JW, et al. Role of ventilation in airborne transmission of infectious agents in the built environment- a multi-disiplinary systematic review. Indoor Air. 2007;17:2-18.

33. Kao PH, Yang RJ. Virus diffusion in isolation rooms. J Hosp Infect. 2006;62:338-45.

34. Tellier R. Review of aerosol transmission of influenza A virus. Emerg Infect Dis. 2006;12:1657-62.

35. Bischoff WE, Bassetti S, Bassetti-Wyss BA, Wallis ML, et al. Aiborne dispersal as a novel transmission route of coagulase-negative staphylococci, interaction between coagulase-negative staphylococci and rhinovirus infection. Infect Control Hosp Epidemiol. 2004;25:504-11.

36. McWilliams RG, Blanshard KS. The risk of blood splash contamination during angiography. Clin Radiol. 1994;49:59-60.

37. Tellier R. Aerosol transmission of influenza A virus: a review of new studies. J R Soc Interface. 2009;6:783-90.

38. Brankston G, Gitterman L, Hirji Z, Lemieux C, Gardam M. Transmission of influenza A in human beings. Lancet Infect Dis. 2007;7:257-65.

39. Aintablian N, Walpita P, Sawyer MH. Detection of Bordetella pertussis and Respiratory syncytial virus in air samples from hospital rooms. Infect Control Hosp Epidemiol. 1998;19:918-23.

40. Moser MR, Bender TR, Margolis HS, Noble GR, Kendal AP, Ritter DG. An outbreak of influenza abroad a commercial airliner. Am J Epidemiol. 1979;110:1-6.

41. Morawska L. Droplet fate in indoor environments, or can we prevent the spread of infection? Indoor Air. 2006;16(5):335-47.

42. Creamer E, Shore AC, Deasy EC, et al. Air and surface contamination patterns of methicillinresistant Staphylococcus aureus on eight acute hospital wards. J Hosp Infect. 2014;86:201-8.

43. Best EL, Fawley WN, Parnell P, Wilcox MH. The potential for airborne dispersal of Clostridium difficile from symptomatic patients. Clin Infect Dis. 2010;50:1450-7.

44. Pirtle EC, Beran GW. Virus survival in the environment. Rev Sci Thech. 1991;10:733-48.

45. Casanova LM, Rutala WA, Weber DJ, Sobsey MD. Corona virus survival on healthcare personnel protective equipment. Infect Control Hosp Epidemiol. 2010;31:560-1.

46. Casanova LM, Waka B. Survival of surrogate viruses on N95 respirator material. Infect Control Hosp Epidemiol. 2013;34:1334-5.

47. Coulliette AD, Perry KA, Edwards JR, Noble-Wang JA. Persistence of the 2009 pandemic influenza A (H1N1) virus on N95 respirators. Appl Environ Microbiol. 2013;79:2148-55.

48. Fisher EM, Richardson AW, Harpest SD, Hofacre KC, Shaffer RE. Re-aerosolization of MS2 bacteriophage from an N95 filtering facepiece respirator by simulated coughing. Ann Occup Hyg. 2012;56:315-25.

49. Viscusi DJ. Bergman MS Elmer BC, Shaffer RE. Evaluation of five decontamination methods for filtering face-piece respirators. Ann Occup Hyg. 2009;53:815-27.

50. Milton DK, Fabian MP, Cowling BJ, Grantham ML, McDevitt JJ. Influenza virus aerosols in human exhaled breath: particle size, culturability, and effect of surgical masks. PLoS Pathog. 2013;9:e1003205.

51. Chen SC, Chio CP, Jou LJ, Liao CM. Viral kinetics and exhaled droplet size affect indoor transmission dynamics of influenza infection. Indoor Air. 2009;19:401-13.

52. Cowling BJ, Ip DKM, Fang VJ, et al. Aerosol transmission is an important mode of influenza A virus spread. Nat Commun. 2013;4:1935.

53. Yang W, Marr C. Dynamics of airborne influenza A viruses indoors and dependence on humidity. PLoS One. 2011;6:e21481.

54. Yang W, Marr LC. Mechanisms by ambient humidity mayaffect viruses in aerosols. Appl Environ Microbiol. 2012;78:6781-8.

55. Weber T, Stilianakis NI. Inactivation of influenza A viruses in the environment and modes of transmission: a critical review. J Infect. 2008;57:361-73.

56. Teunis PFM Brienen N, Kretzschmar MEE. High infectivity and pathogenity of influenza A virus via aerosol and droplet transmission. Epidemics. 2010;2:215-22. 
57. Bean B, More BM, Sterner B, Peterson LR, Gerding DN, Balfour HH. Survival of influenza viruses on environmental surfaces. J Infect Dis. 1982;146:47-51.

58. Thomas Y, Vogel G, Wunderli W, et al. Survival of influenza viruses on banknotes. Appl Environ Microbiol. 2008;74:3002-7.

59. Mulin B, Rouget C, Clement C, et al. Association of private isolation rooms with ventilatorassociated Acinetobacter baumannii pneumonia in surgical intensive-care unit. Infect Control Hosp Epidemiol. 1997;18:499-503.

60. Rice N, Streifel A, Vesley D. An evaluation of hospital special-ventilation-room pressures. Infect Control Hosp Epidemiol. 2001;22:19-22.

61. Greatorex JS Digard P, Curran MD, et al. Survival of influenza A (H1N1) on materials found in householders: Implications for infection control. PLoS One. 2011;6:e27932.

62. Tang JW, Eames In Li Y, et al. Door-opening motion can potentially lead to a transient breakdown in negative-pressure isolation conditions: the importance of vorticity and buoyancy airflows. J Hosp Infect. 2005;61:283-6.

63. Dancer SJ. Mopping up hospital infection. J Hosp Infect. 1999;43:85-100.

64. MacIntyre CR, Wang Q, Rahman B, et al. Efficacy of face masks and respirators in preventing upper respiratory tract bacterial colonization and co-infection in hospital healthcare workers. Prev Med. 2014;62:1-7.

65. Cowling B, Chan KH, Fang VJ, et al. Face masks and hand hygiene to prevent influenza transmission in households: a cluster randomized trial. Ann Intern Med. 2009;151:437-46.

66. Cowling B, Fung ROP, Calvin KY, et al. Preliminary findings of a randomized trial of nonpharmaceutical interventions to prevent influenza transmission in households. PLoS One. 2008;3:e2101.

67. MacIntyre CR, Cauchemez S, Dwyer DE, et al. Face mask use and control of respiratory virus transmission in households. Emerg Infect Dis. 2009;15:233-41.

68. Weber A, Willeke K, Marchioni R, et al. Aerosol penetration and leakage characteristics of masks used in the healthcare industry. Am J Infect Control. 1993;21:167-73.

69. Harnish DA, Heimbuch BK, Husband M, et al. Challenge of N95 filtering face-piece respirators with viable H1N1 influenza aerosols. Infect Control Hosp Epidemiol. 2013;34:494-9.

70. Lawrence RB, Duling MG, Calvert CA, Coffey CC. Comparison of performance of three different types of respiratory protection devices. J Occup Environ Hyg. 2006;3:465-74.

71. Balazy A, Toivola M, Adhikari A, et al. Do N95 respirators not provide $95 \%$ protection level against airborne viruses, and how adequate are surgical masks? Amer J Infect Control. 2006;34:51-7.

72. Grinshpun SA, Haruta H, Eninger RM, et al. Performace of an N95 filtering face-piece particulate respirator and a surgical mask during human breathing: two pathways for particle penetration. J Occup Environ Hyg. 2009;6:593-603.

73. Derrick JL, Li PTY, Tang SPY, Gomersall CD. Protecting staff against airborne viral particles: in vivo efficiency of laser masks. J Hosp Infect. 2006;64:278-81. 